\title{
Mechanisms of Tropical Atlantic SST Influence on North American Hydroclimate Variability*
}

\author{
Yochanan Kushnir, Richard Seager, Mingfang Ting, Naomi Naik, and Jennifer Nakamura \\ Lamont-Doherty Earth Observatory, The Earth Institute at Columbia University, Palisades, NY
}

Submitted to the Journal of Climate for consideration in the US CLIVAR

Drought Working Group Special Issue.

March 2009

* Lamont-Doherty Earth Observatory Contribution Number XXXX 


\begin{abstract}
The dynamical mechanisms associated with year-to-year variability in tropical North Atlantic (TNA) sea surface temperatures (SSTs) during the cold and warm half of the hydrological year (October-September) are examined. Observations indicate that during both seasons warmer than normal TNA SSTs are associated with a reduction of precipitation over the North America, west of about $90^{\circ} \mathrm{W}$ and that that effect can be up to $30 \%$ of the year-to-year seasonal precipitation RMS variability. This finding confirms earlier studies with observations and models. While not as large as the seasonal effects of ENSO during the cold season, the Atlantic impact, per one standard deviation of TNA SSTs, is larger than that of the former during the warm season.
\end{abstract}

When the observed association between TNA SST anomalies and global and regional (North American) precipitation and sea level pressure variability are compared with the output from an atmospheric general circulation model (AGCM) forced with observed SSTs, we find that the SST variability can be viewed as the cause for circulation and rainfall variability. The mechanism of the upstream influence on the American West is seasonally dependent, as confirmed by a set of experiments with a linear general circulation model forced with the tropical heating field derived from the full AGCM response. In the warm half of the year, the SST-induced increase in TNA convection, leads to a weakening of the North Atlantic subtropical anticyclone and a related anomalous southward flow over the American West, a situation that is associated with subsidence over the continent. In the cold season, we identify a response similar to the warm season over the subtropical Atlantic but there is also a suppression of convection over the equatorial Pacific, which causes a weakening of the Aleutian low. This situation is similar to the impact of La Niña on the extratropics, including North American precipitation, although it is much weaker in amplitude. 


\section{Introduction}

The nature and cause of North American hydroclimate variability is a subject of heightened concern because of the recent droughts ${ }^{1}$ in the American West ${ }^{2}$ and Northern Mexico (Seager 2007 and Seager et al. 2009) and because projections of anthropogenic influence on the climate of the $21^{\text {st }}$ Century indicate a broad model agreement regarding the region's turn towards increasing aridity (Seager et al. 2007). The latter finding, based on output from climate models that participated in the Intergovernmental Panel on Climate Change (IPCC) Fourth Assessment Report (AR4) suggest that droughts such as the present one, may become a permanent feature of the region.

Many recent studies examine the interannual and multi-year variability of rainfall and other indicators of drought in the North America (e.g., Hoerling and Kumar 2003; Cook et al. 2004; McCabe et al. 2004; Schubert et al. 2004a; Acuna-Soto et al. 2005; Seager et al. 2005b). The North American region west of the Mississippi $\left(\sim 90^{\circ} \mathrm{W}\right)$ is relatively dry outside of a narrow band along the American West Coast and in the high mountain areas of the northern Rockies. Its hydrological state is thus vulnerable to climatic fluctuations on interannual and longer time scales. The climatic history of the region is dotted with long, dry periods that affected the natural environment, human settlement and activities and which bore on water right agreements and policies. Better understanding of the physical setting for such events is important for future planning and predictions. The present work is concerned with the dynamical mechanisms that govern such hydroclimate variations, in particular on interannual-to-decadal time scales.

\footnotetext{
${ }^{1}$ By "drought" we refer to a meteorological drought, i.e., a significant deficit of rainfall or a significant negative anomaly in the difference between precipitation and evaporation.

${ }^{2}$ In this paper we shall refer to the American West as the contiguous U.S. and Northern Mexico area lying west of $90^{\circ} \mathrm{W}$.
} 
Recent modeling studies indicate that the main regulating mechanism of interannual and multiyear variability of precipitation in the American West, are low frequency anomalies in tropical Pacific sea surface temperatures (SSTs). It is well known that tropical Pacific SSTs exhibit large fluctuations with a period of 2 to 7 years, which are related to the El Niño/Southern Oscillation (ENSO) phenomenon. These fluctuations are not symmetric around the mean neither are they regular. Thus when averaged over a time interval equal or longer than the ENSO period, they leave a small, but dynamically significant residual, either positive or negative, on eastern equatorial Pacific (EEP) SSTs. Evidence that these small anomalies are important to North American climate, comes from the work of Schubert et al. (2004a and b) and Seager et al (2005b). Seager et al., in particular, integrated two ensembles of the National Center for Atmospheric Research (NCAR) Community Climate Model 3 (CCM3), both forced with a century and a half (1856-2006) of observed, monthly-mean SSTs; one ensemble was forced with global SSTs and the other with SSTs prescribed only in the tropical Pacific ${ }^{3}$. The two ensembles yielded extremely similar results regarding the variability of rainfall in the American West. Both were in good agreement with the observed record, showing that multi-year droughts in the American West occur when SST in the EEP are colder than normal, on average, for several years in a row. The reverse is also true, that is, protracted warming in the EEP leads to a wet interval in the American West (Huang et al. 2005). The studies of Schubert et al. (2004a and b) yielded similar results using a different climate model (the National Aeronautics and Space Administration Seasonal-to-Interannual Prediction Project model \#1). They demonstrated the importance of the tropical Pacific forcing by comparing the results of ensembles forced with observed global SSTs and several idealized integrations with SSTs prescribed in different ocean basins.

\footnotetext{
3 The latter model calculated the SST variability outside of the tropical Pacific by using an entraining ocean mixed layer model, responding locally to the variability of air-sea fluxes and a fixed (calendar-monthdependent) flux adjustment to climatology (see Seager et al. 2005b for details).
} 
The explanation to the EEP SST impact lies in the response of the atmosphere to ENSO (see Seager et al. 2003 and 2005a). In particular, warmer/colder than normal EEP SSTs lead to an overall warming/cooling of the tropical atmosphere. This causes the maximum in the westerlies to move equatorward/poleward from its mean position and changes the pattern of baroclinic-eddy momentum-flux convergence in the upper troposphere, thus affecting the mean meridional circulation (MMC). The result is a zonally and hemispherically symmetric anomalous ascent/decent in the midlatitudes, which in the Northern Hemisphere enhances/suppresses precipitation in the latitude band $25^{\circ} \mathrm{N}$ to $45^{\circ} \mathrm{N}$. In winter, the midlatitude response over North America is enhanced by a stationary-wave anomaly, caused by the changes in the location of the convective heating in the tropics, which forces a low/high pressure over the Gulf of Alaska and the American Western seaboard and ascent/descent over the American West (a phenomenon known as the Pacific/North American Pattern, PNA, see e.g., Horel and Wallace 1981; Wallace and Gutzler 1981; and Trenberth et al. 1998). Both the zonally symmetric and wave-like response to ENSO thus lead to an anomalously wet/dry winters over North America, for El Niño/La Niña conditions, respectively, particularly in the West and in the South. In the summer the local height anomalies are weaker, yet similar in phase and precipitation is probably also affected by changes in the local moisture source from the ground, carried over from the preceding winter (seasonal moisture recycling).

As indicated above, the results of Schubert et al. (2004a) and Seager et al. (2005b) suggest that the reason for the persistence of drought conditions (and for that matter, also persistent wet conditions) lies in SST anomalies that, while smaller in amplitude (and broader in scale), are ENSOlike and modulate the state of the tropical Pacific on decadal time scales (Zhang et al. 1997; Seager et al. 2004). During the "Dust Bowl" drought of the 1930s, for example, EEP SST were on average colder than normal by about $0.2^{\circ} \mathrm{C}$ and there was no major El Niño during the entire decade. While there were interannual variations in the strength of this anomaly, the almost decade-long weak 
cooling was the leading cause, according to the models, for the drought event ${ }^{4}$. However, Schubert et al. (2004b) pointed out that during these years, North Atlantic SSTs were considerably warmer than normal, north of the equator and showed that the tropical North Atlantic warmth was important for the persistence of the drought. This was done using a series of idealized experiments, in which the model was integrated with SSTs corresponding to the average conditions during the entire Dust Bowl era, alternately prescribed in different parts of the world ocean.

That the Atlantic influences North American hydroclimate was suggested earlier in the observational studies of Enfield et al. (2001) and McCabe et al. (2004). In the North Atlantic, a multidecadal timescale "oscillation" of SST stands out clearly even in temporally unfiltered data. The phenomenon was referred to as the Atlantic Multidecadal Oscillation (AMO) by Kerr (2000) but had been described earlier by Kushnir (1994) and Schlesinger and Ramankutty (1994). Enfield et al. (2001) argued for the existence of a causal link between the warm phase of the AMO and relatively warm and dry climate of the North America during the thirty-year interval 1931-1960, during which the Dust Bowl and the 1950's droughts occurred. After 1960 the Atlantic began to cool and for almost three decades the North American climate turned wetter and colder. McCabe et al. (2004) looked at the association of bi-decadal North American drought frequency with both the AMO and its Pacific counterpart: the Pacific Decadal Oscillation (PDO, Zhang et al. 1997) in 20 ${ }^{\text {th }}$ century observations. Their results supported the conclusions of prior observational studies and are consistent with the recent modeling studies, described in previous paragraphs.

The latest model study looking at the Atlantic influence on North America hydroclimate was reported by Sutton and Hodson (2005 and 2007). These articles provide a detailed analysis of the role of the AMO in precipitation variability around the Atlantic Basin. The study consisted of a set of controlled atmospheric general circulation model (AGCM) experiments, using the Hadley Center

\footnotetext{
${ }^{4}$ Recently it was shown (Cook et al., 2008) that the dust, generated by soil erosion played an secondary, yet important role in shaping the location and intensity of the drought.
} 
HadCM3 model forced in the North Atlantic with an SST anomaly pattern corresponding to the AMO. The tropical AMO anomaly was enhanced by a factor of four and each of the two model integrations was carried out for 40 years, thus providing a robust signal of the atmospheric response to the AMO in either phase. The results show a persistent, year-round tropical response that consists of an increase in rainfall in the tropical North Atlantic during a warm AMO phase, combined with reduced rainfall in the eastern tropical Pacific and Indian Oceans. In the American West, significant negative rainfall anomalies occur during the boreal spring and summer when the North Atlantic is warm. Repeating the model integrations with only the north tropical Atlantic portion of the AMO SST anomaly yielded similar results in these regions and difference were found only over the highlatitude North Atlantic Ocean. Sutton and Hudson (2005 and 2007) concluded that as far as the impact of the Atlantic on North American hydroclimate is concerned, it is the tropical SSTs that are important.

The goal of this paper is to add to the work of Sutton and Hodson and study further the pattern and mechanisms of the Atlantic Ocean influence on North American hydroclimate variability. In the present work we use a different AGCM, namely the U.S. National Center of Atmospheric Research Community Climate Model 3 (CCM3), forced with time varying SSTs (as in Seager et al. 2005b). In this way we test the sensitivity of the Sutton and Hodson result to the model and its forcing methodology. The experimental methodology also helps to address the role of the Atlantic relative to the Pacific in forcing North American hydroclimate variability. In addition we employ a linear, primitive equation model to test the hypotheses regarding the dynamical mechanisms of Atlantic SST forcing, derived from observations and the full AGCM simulations.

In section 2 we describe the observational datasets and the modeling methodology used in the study. The results of the analyses of observations and AGCM output are described in sections 3 and 
4 and the linear model results are described in section 5. A summary of the result is presented in the concluding section.

\section{Observations and Models}

\subsection{Observations}

For observations we use a wide range of gridded analyses of climate observations. For global precipitation variability, covering both ocean and land regions, we analyze the satellite-gauge blend of the 1979 onward, "Global Precipitation Climatology Project" (GPCP, Huffman et al. 1997). The rather short GPCP record is replaced by the NOAA PREC/L data (Chen et al. 2002, available since 1948) when examining in detail the variations of precipitation over North America. Atmospheric data (specifically, sea level pressure data) are taken from the NCEP-NCAR Reanalysis Project (Kalnai et al. 1996; Kistler et al. 2001).

For indices of tropical Pacific and tropical Atlantic SST variability we use the NINO3.4 index, defined as the normalized SST-average in the region lying between $170^{\circ} \mathrm{W}$ and $120^{\circ} \mathrm{W}$ and between $5^{\circ} \mathrm{S}$ and $5^{\circ} \mathrm{N}$ and the normalized SST-average over the tropical North Atlantic between the equator and $30^{\circ} \mathrm{N}$ (hereafter TNA SST index).

\subsection{Model experiments}

This study follows the methodology used in our previous works, where a relatively large ensemble of AGCM integrations, all forced with the same prescribed SST conditions, is analyzed to determine the response common to all ensemble members. In Seager et al. (2005b) we pursued the hypothesis that decadal equatorial Pacific SST variability is a primary forcing of multi-year droughts in the American West. Three ensembles of the National Center for Atmospheric Research (NCAR) Community Climate Model (CCM), version 3 (Kiehl et al. 1998) were integrated for that purpose, each with different SST forcing. One with global SST variability prescribed, month-by-month, from 1856 to the present (this experiment is dubbed GOGA, for Global Ocean Global Atmosphere). For 
SST forcing we used a combination of the Lamont optimally smoothed SST dataset (Kaplan et al. 1998) in the tropics and before 1870 and HadISST (Rayner et al. 2003) elsewhere. The two other ensembles were integrated with the same SST forcing but limited to the tropical Pacific region, between $30^{\circ} \mathrm{S}$ and $30^{\circ} \mathrm{N}$. Elsewhere SST were either prescribed at their monthly climatological values (an experiment dubbed POGA, for Pacific Ocean Global Atmosphere, ensemble) or allowed to deviate locally from climatology with the change in local atmospheric forcing, using a two-layer, entraining ocean mixed layer (ML) model (POGA-ML). Easch of these ensembles included 16 members. For more details about these experiments see Seager et al. (2005b).

Here we make use of the GOGA ensemble but in addition, for the purpose of clearly identifying the Atlantic influence, a new model ensemble was integrated, using the same climate model and similar methodology as in the POGA ensemble. The difference here is that SST variability was prescribed only in the tropical Atlantic region, between $30^{\circ} \mathrm{S}$ and $30^{\circ} \mathrm{N}$ leaving climatological conditions elsewhere. We dubbed this experiment TAGA, for Tropical Atlantic Global Atmosphere. In that way the experiment resembles the approach of Sutton and Hodson (2005 and 2007), who prescribed observed SST in two ensembles one with only the tropical North Atlantic forcing. However, they used a fixed SST pattern, corresponding to the difference between the warm Atlantic years (1930 to 1960) and the cold years (1960 to 1990) while here we prescribe the entire $\sim 150$ year SST history. This allows the model to vary internally as well as respond to the changing, prescribed SST in the tropical Atlantic and makes it possible to apply the same analysis methodologies to the models as to the observations. It also makes it possible to study the temporal properties of the response. The choice of limiting the prescribed SST to the tropical Atlantic only was made on the basis of the results of Sutton and Hodson and of Schubert et al. (2004a) that indicate that, as far as the Atlantic influence is concerned, North American hydroclimate is sensitive mainly to SST variability in that region. 
In addition to the use of a complex, full AGCM with realistic atmospheric variability, we employ in this study a linear, dry, primitive equation model, to test hypotheses emerging from the analysis of the former. The linear model is an exact linearization of the NOAA/Geophysical Fluid Dynamics Laboratory (GFDL) spectral model with R30 resolution and 14 vertical layers, linearized around a realistic, 3-dimensional basic state, as in Ting and Yu (1998). In this particular application the model was forced with a three-dimensional heating field between $30^{\circ} \mathrm{N}$ and $30^{\circ} \mathrm{S}$. The heating field was derived from the TAGA ensemble mean by regressing on SST averaged in the tropical North Atlantic Ocean (eq. to $30^{\circ} \mathrm{N}$ ) region. To suppress high-frequency transients, the model was highly damped. The model was integrated for 50 days and an average of the last 20 days of the integration is used to represent the stationary response.

\section{Observed association between tropical Atlantic SST and North American Droughts}

Seager et al. (2009) recently studied the relationship between the TNA and NINO3.4 time-series and North American precipitation, by season. They used gridded gauge data from the Universidad Nacional Autónoma de México (UNAM), which covers the U.S., Mexico, Central America and northern South America. Using multiple regression analysis Seager et al. showed that the major impact of both TNA and EEP SST is much more coherent in the cold season (which that study defined as November-April) than in the warm season (defined as May-October). In Figs. 1 and 2 we present results of a similar multiple regression analysis applied to the NOAA PREC/L dataset for

the years 1948 to 2007. The data are stratified by season dividing the "hydrological year" into its cold season (October-March) and warm season (April-September) halves. The regression coefficients are divided by the seasonal precipitation RMS value calculated over all years. The results are consistent with those of Seager et al. (2009, see their Figs. 1 and 2) and with a similar calculation using the shorter GPCP record (not shown), indicating the robustness of the main features.

- Figure 1 about here - 
In the cold season ENSO influence (panel c) is roughly twice as large as that of TNA SST (panel a). As expected, a warm equatorial Pacific event (El Niño) is associated with larger than normal (up to $60 \%$ of the total seasonal RMS variability) cold-season precipitation over the southern U.S. states, over the American West and over northern Mexico. Warmer than normal TNA SSTs are associated with drier than normal conditions in most of the same locations but prominently over southwestern U.S. and northwestern Mexico. In this region, negative anomalies reach up to $30 \%$ of the seasonal precipitation RMS value. This indicates a competition between the Pacific and the Atlantic influences during ENSO events. That is because during the cold season, ENSO forces the same-sign SST anomaly in the tropical Atlantic. Thus, a Pacific warm/cold event forces an increase/decrease in North American precipitation and in the same time a warming/ cooling of the TNA region, an effect that leads to a weakening/strengthening of North American precipitation. This competition is obviously won by the Pacific event but the overall effect is a weaker influence. Note however, that the TNA displays it own variability which could, at time, work in consort with ENSO to increase the overall effect.

A secondary region of cold-season reduced precipitation linked to positive TNA SST anomalies lies roughly along the Mississippi Valley. This is consistent with the finding of investigators (e.g., Enfield et al. 2001; McCabe et al. 2004), who looked at the long-term impact of the Atlantic Ocean on North American precipitation. In the warm season warmer than normal TNA SSTs are linked to drying along the U.S.-Canada border, extending from the Great Lakes to the Canadian Plains (Fig. 1b). A second region of drying is seen along the U.S.-Mexico border with the largest values reaching deep into Mexico. However the drying associated with anomalously warm TNA SSTs is more pronounced in the cold season (panel A) than in the warm season (Panel c).

The global SLP and precipitation patterns associated with tropical Pacific and tropical Atlantic SST variability were derived in a similar manner, using multiple regressions on the NINO3.4 index 
and the TNA SST index. The analysis is confined to the years 1979 to 2007 to match the satellite record, which provides precipitation estimates over the oceans. Figure 2 presents only the TNA related patterns emerging from the multiple regression analysis. The NINO3.4 regression patterns (not shown) display the well-known large, tropical Pacific precipitation anomalies and the weaker ones forced over other parts of the world. In SLP, there is a negative cold-season anomaly over the North Pacific and eastern tropical Pacific (e.g., Trenberth et al. 1998; Seager et al. 2005a). A similar but weaker pattern is seen in the warm-season months.

- Figure 2 about here -

The cold-season SLP regression on TNA SST (Fig. 2a) displays a dipole pattern over the North Atlantic, which resembles the North Atlantic Oscillation (NAO). The sense of the relationship is such that warmer than normal TNA SST are associated with a negative NAO state. This is consistent with the notion that a negative NAO forces warm SSTs over the subpolar and TNA regions (Seager et al. 2000; Hurrell et al., 2003) and therefore appears in the instantaneous regression. However, as we shall see below, the subtropical low-pressure anomaly may also include a forced response to the warm TNA SST.

Over the Pacific, the cold season SLP pattern in Fig. 2a displays a pattern similar to that associated with (and forced by) cold EEP SST anomalies (the cold phase of Pacific ENSO, see Trenberth et al. 1998). Together, the North Atlantic and North Pacific circulation anomalies of Fig. 2a are associated with southward flow over the U.S at the surface and aloft (the pressure response is equivalent barotropic, not shown). Such flow should be associated with dynamically driven subsidence, as argued in Seager et al. (2005a), and hence with a negative, cold-season precipitation anomaly over the region.

In the Pacific sector, the SLP anomalies in Fig. $2 \mathrm{a}$ are symmetric about the equator, with the high-pressure anomalies over the eastern North Pacific paralleled by an anomaly of the same sign in 
the South Pacific. This hemispheric symmetry is consistent with tropical forcing. An examination of the precipitation anomaly field indicates that the midlatitude anticyclone pair in the middle of the Basin straddle a negative anomaly situated in the central tropical Pacific and flanked by positive anomalies to the west, over the western equatorial Pacific and to the east, over the EEP and the TNA. As we shall argue below, based on results from a hierarchy of global models, this weak "La Nina-like" arrangement is actually forced remotely by the warm TNA SST and subsequently causes the hemispherically symmetric response in the extratropics.

The warm season SLP pattern associated with TNA SST (Fig. 2b) is, to some extent, a weaker expression of the cold-season one. Here too we find enhanced precipitation over the western TNA and a low-pressure anomaly over the subtropical North Atlantic. Over North America, precipitation is reduced. In the Pacific, precipitation increases west of $150^{\circ} \mathrm{W}$ but mainly over the Maritime Continents and the Indian Ocean. This is associated with a subtropical anticyclonic pair straddling the equator in the western Pacific and negative subtropical precipitation anomalies.

We note that because of the short record of satellite-based precipitation estimates, these results should be viewed with caution. However, we did confirm that the main SLP features in Fig. 2 are reproducible by repeating the multiple regression analysis with a longer re-analysis record and with the century long HadSLP dataset (not shown). In the next section we compare the observed patterns with the AGCM results, which by their similarity to their observed counterparts add, further credence to the credence of these relations.

\section{AGCM results}

Figure 3 displays the results of a multiple regression analysis applied to the GOGA ensemblemean output. Both the global SLP and precipitation fields are analyzed following the same procedure applied to the observations in Fig. 2. Here too, only the regression pattern corresponding to TNA SSTs is shown. The analysis is performed over the same time interval used for the 
observations (1979 to 2007) for better comparison. The resemblance to observations (Fig. 2) is striking, considering that the regression in Fig. 2 is derived based on the "single realization" provided by the observations while the model results are based on an ensemble-average of 16 independent realizations, but forced with the same global SST conditions. Ensemble averaging strongly reduces the variability not related to the prescribed SSTs and thus the fields should be less "noisy". In addition we should consider the fact that the observed relationship includes atmospheric variability that could have caused the TNA SST anomalies (such as the NAO) and not only the response to the latter. In the model, the atmospheric variability has no influence on the state of the ocean and thus has been averaged out. The model results however, may include spurious features that are unphysical such as the tendency to precipitate over areas with prescribed, warmer than normal SST that were created by atmospheric forcing (e.g, reduced clouds or changes in winds).

- Figure 3 about here -

The model results confirm that over the TNA, the circulation responds to SST in both cold and warm seasons by increased convection activity and a weak, low-pressure anomaly. In the cold season (Fig. 3a and c) the model displays a low-pressure anomaly over the entire North Atlantic Basin, in contrast with the observations, where a large positive anomaly is centered just east of Greenland (Fig. 2a). This discrepancy can be explained by the fact that a warmer than normal TNA can be forced by the NAO in its negative phase with high pressure over the sub-polar Atlantic (e.g., Seager et al. 2000). The simulated high-pressure anomaly over the Pacific is more robust than in observations and about twice as strong. Circulation features over the South Pacific are weaker than in observations but consistent in phase (the noisy pattern over Antarctica in observations can be attributed to the short record and to deficiencies in the re-analysis over this data-sparse region). In the warm season (Fig. 2b and Fig. 3, b and d) the agreement is in the low-pressure anomaly over the 
TNA region as well as the anomaly centers over the Pacific, both north and south of the equator, although here the North Pacific anticyclonic anomaly is weak.

The general layout of tropical precipitation anomalies in the GOGA TNA regression pattern (Fig. 3, a and b), confirms the observed features discussed above in section 2. There is a positive anomaly over the TNA region, with a maximum of $\sim 1 \mathrm{~mm}$ day $^{-1}$ over the Caribbean and southern Central America, extending into the eastern tropical Pacific. The pattern, in particular during the summer, resembles the layout of the ITCZ and corresponds to its intensification due to warmer NTA SST. In the model the positive precipitation anomalies over the Caribbean are stronger than in observations. This could be due to the ensemble averaging and/or to the fact that models with prescribed SST are known to display excessive convective response to warm anomalies (e.g., Biasutti et al., 2006). The precipitation anomalies in the tropical Pacific are generally negative, reaching $\sim 1$ $m m$ day $^{-1}$ in the center of the Basin, during the cold season (Fig. 4a).

The TAGA model response to NTA SST (derived by simple linear regression on the TNA SST index) is shown in Fig. $3 \mathrm{c}$ and d. The pattern agrees in general with the corresponding GOGA multiple regression results. However, several exceptions are worth noting: One is the reduced strength of the precipitation anomalies over the tropical Pacific compared to GOGA. Consistent with that is a weaker SLP anomaly in the North Pacific during winter. In the Atlantic the lowpressure anomaly over the northern basin is stronger than in GOGA consistent with the stronger increase in precipitation over the TNA, particularly in the Caribbean (here the anomaly is twice as large as the GOGA anomaly, reaching $\left.\sim 2 \mathrm{~mm}^{\text {day }}{ }^{-1}\right)$. Also noticeable is a large negative precipitation response over the tropical Indian Ocean, particularly during the warm season, when the anomaly over the Bay of Bengal reaches $-1 \mathrm{~mm} \mathrm{day}^{-1}$. We attribute the absence of such anomalies over the Indian Ocean in the GOGA ensemble mean to the prescribed SST variability there (TAGA has climatological SST prescribed outside the tropical Atlantic). Observed SST variability in that ocean 
basin shows considerable coherence with TNA SST variability, mainly due to the gradual warming of most of the tropics during the $20^{\text {th }}$ century. The warming trend in GOGA Indian Ocean SST could lead to increased convection and an overall weaker drying response.

Finally, we zoom in on the details of the TNA impact on North American precipitation. Figure 4 shows the simulated seasonal change in precipitation, relative to the climatological RMS value, calculated as in Fig. 1, using the GOGA ensemble mean output from 1948 to 2007. The most glaring discrepancy between the model and the observations is the tendency of the drying associated with warm TNA SST to occur only south of $\sim 40^{\circ} \mathrm{N}$ with stronger than normal rainfall to the north, over Canada. In observations (Fig. 1) most of that area also exhibited drying. Moreover, the model drying tends to be concentrated over the Southwest and northern Mexico and misses the observed negative anomalies over the Mississippi River Basin. The overall level of the impact is as high as $20-30 \%$ of the seasonal precipitation RMS value.

- Figure 4 about here -

\section{Linear model results}

As described in section 2, the linear model was forced with the tropical-region, threedimensional heating field, derived by regressing the TAGA AGCM ensemble-mean output diabatic heating field on the TNA SST index, by season. The horizontal pattern of the vertically averaged heating (not shown) mimics, as expected, the pattern of precipitation anomaly shown in Fig. 3. The anomaly varies somewhat between seasons with a larger suppression of tropical Pacific heating north of the equator during the warm season and south of the equator in the cold season. This shift is consistent with the annual migration of the Pacific ITCZ (e.g., Waliser and Gautier 1993), with the suppression being large where the ITCZ main convection activity occurs.

Figure 5 shows the vertical structure of the heating regression averaged between $20^{\circ} \mathrm{S}$ and $20^{\circ} \mathrm{N}$, where the largest precipitation anomalies are located. The figure displays heating over the tropical 
Atlantic Basin, associated with increased convection there and elevated cooling almost everywhere else. The cooling is associated with the suppressed convection over the Pacific and Indian Ocean Basins. There is weak warming in a shallow layer in the lower troposphere in the tropical Pacific. However, the elevated cooling is the most likely feature to affect the extratropical regions, as is evident from the forced linear model results discussed below. The seasonal differences are small and are mainly associated with a stronger tropical Atlantic signal in the warm season. A multiple regression of the GOGA heating field on the TNA SST index (not shown) yields qualitatively similar results except for the Indian Ocean region, where the signal is weakly positive, consistent with the precipitation field in Fig. 3.

- Figure 5 about here -

When forcing the linear model, the imposed heating was limited to the latitude belt of $30^{\circ} \mathrm{S}-30^{\circ} \mathrm{N}$. The model was integrated with full tropical heating, TNA only heating $\left(100^{\circ} \mathrm{W}\right.$ to $\left.0^{\circ}\right)$, and Pacific only heating $\left(110^{\circ} \mathrm{E}-100^{\circ} \mathrm{W}\right)$. This was done in order to explore the hypothesis that the circulation responds not only to the heating in the immediate locality of the imposed TNA SST anomaly but also to its influence on heating over other tropical regions. The results are not very sensitive to the exact choice of these boundaries. Figure 6 displays the low- and upper-troposphere, warm-season stream function response of the linear model to the all-tropics heating. During this season the changes in convection over other ocean basins do not seem to contribute to the height changes over the Atlantic and the Americas (not shown). The full TAGA AGCM streamfunction regressions on TNA SST are shown for comparison in the top two panels.

Over the Atlantic and the Americas, the TAGA response to SST imposed in the tropical Atlantic (Fig. 6, panels a and b) is consistent with the "Gill response" to tropical heating (Gill, 1980; Jin and Hoskins, 1995; Ting and Yu, 1998). With TNA heating only (not shown) the response over the Atlantic and the Americas is similar, confirming that the "chain of events" in summer, is that warm 
SST anomalies in the TNA region lead to an increased convection, mainly in the core of the Atlantic ITCZ region, which forces a pair of low-level cyclonic circulation anomalies straddling the heating center. Aloft there is a pair of anticyclones. The impact of the Caribbean-centered, low-level cyclone over the American West is to induce an anomalous southward flow and thus, anomalous subsidence and a negative precipitation anomaly. What seems to be unrelated to Atlantic heating is the large, low-troposphere response over the Indian Ocean, which is simulated by the linear models only when the entire tropical heating pattern is enforced. The impact of Pacific heating alone on the summer circulation is negligible (not shown).

- Figure 6 about here -

In observations and the models used here, the tropical Atlantic is also responsible for reduced precipitation over North America in winter. This winter drying seems to be linked with a more complex response than that found in summer. This cold season response is studied further in Fig. 7. Outside of the immediate vicinity of the heating maximum in the TNA, the response is equivalent barotropic, consistent with theory. The mid-tropospheric streamfunction response in Fig. 7 thus represents a troposphere-deep pattern in both the North Pacific and North Atlantic. Only in the TNA region is the response baroclinic (as anticipated from a heating forced response), with a highpressure anomaly in the upper troposphere overlying a local, low-level, low-pressure anomaly (not shown).

- Figure 7 about here -

To reproduce close to the full strength and detailed response of the cold-season atmosphere to TNA SST, the linear model had to be forced by the full tropical heating field (Compare Fig. 8 panels $\mathrm{a}$ and $\mathrm{b}$. The small discrepancies in the strength of the response pattern can be attributed to the absence of transients and/or extratropical heating in the linear model.) With the Atlantic portion of the heating alone, the model responds most strongly (but with lower amplitude than the full heating 
field) over the North Atlantic (Fig. 8c) and with Pacific heating alone the model responds mainly over the North Pacific (Fig. 8d). The tropical convection response to warm Atlantic SST (Fig. 5) is thus important for explaining the weak but significant high-pressure (and La Niña-like) response over the Pacific. Together with the low-pressure response over the North Atlantic these mid-latitude centers induce dynamically driven subsidence over the American West, which suppresses precipitation there. It is therefore important to explore the mechanism by which the Atlantic heating forces convection over the Pacific.

One way in which increased convection over the TNA can leads to suppressed convection over the tropical Pacific is through subsidence. Indeed, an examination of the TAGA tropical vertical motion field reveals broad areas of subsidence consistent with the regions of cooling in Fig. 5 (not shown). However, this pattern of vertical motion cannot be viewed separately from the suppressed convection and thus may not be causal. To explore the forced vertical motion response to tropical Atlantic SST we turn to the linear model experiment with the heating imposed only over the TNA region. Figure 8a displays the average linear model, vertical motion response to TNA heating. Over the tropical Atlantic we find the expected upward motion associated with the heating. Elsewhere the model displays weak subsidence.

- Figure 8 about here -

Another likely mechanism that leads to the remote suppression of convection is the horizontal spreading of high-level warming by equatorial waves, which leads to stabilization of the tropical atmosphere and suppression of convection outside of the immediate region of increased convection. Yulaeva and Wallace (1994) demonstrated the existence of such a mechanism in connection with ENSO. Recently, Chiang and Sobel (2002) invoked this mechanism to explain the remote tropical convection and SST response to ENSO variability. As seen in Fig. 8b, the tropospheric, high-level, tropics-wide warming is the coherent, stationary response to the heating 
prescribed over the tropical Atlantic. The tropical temperature response in the full TAGA (Fig. 9) displays a strong warming signal over the TNA but a weak cooling over the tropical Pacific that is deep in winter (Fig. 9a) and shallow in summer (Fig. 9b). We interpret this pattern as the outcome of an equilibrated response to the reduced convective heating over the Pacific which was triggered by the effect of increased TNA convection on tropical static stability.

- Figure 9 about here -

\section{Summary and Discussion}

Observations and model studies indicate that changes in SST on interannual and longer time scales in the tropical North Atlantic lead to precipitation variability in North America. Positive SST anomalies in the TNA region are associated with negative precipitation anomalies (and droughts) over most of the contiguous U.S., but particularly in the West (Figs. 1 and 2) and over Mexico. This is the case in both halves of the hydrological year: October through March and April through September, with a somewhat larger effect in the cold half of the year. In experiments with a GCM forced with the observed history of SST variability the association between TNA SST and North American precipitation is reasonably well simulated (Fig. 4). Some of the discrepancies can be attributed to the larger impact of sampling variations in the observed record and/or to model biases. This indicates that the observed precipitation regression pattern (Fig. 1) can be attributed to forcing by TNA SST variability.

During the cold season, the change in precipitation associated with a one standard deviation of TNA SST is considerably smaller than the change associated with the Nino3.4 index but in summer the Atlantic influence is larger (Fig. 1). On interannual time scales, the standard deviation of the Niño index is considerably larger than that of TNA SST, thus tropical Pacific SST fluctuations

should dominate the variability of precipitation in North (and Central) America when year-to-year changes are concerned. However, on decadal and multi-decadal time scales, SST variability in both 
ocean regions is comparable and the Atlantic influence should become more important, particularly so in the warms season.

The interplay between the Pacific and Atlantic effects on North American hydroclimate can be discerned in Fig. 10. The figure displays a long time series of an indicator of North American hydroclimate, along with the concurrent, low-frequency variations of Nino3.4 and the TNA SST index. The hydroclimate indicator is the annual, tree-ring-based estimates of Palmer Drought Severity Index (PDSI) provided in the North American Drought Atlas (NADA, Cook et al. 2004). NADA provide a temporally stable fit to the observations in the recent past and a regression-based extrapolation to the pre-instrumental era (which, in some location, covers the last two millennia). Here we use NADA from 1856 to the present and display the average over the American West $\left(25^{\circ} \mathrm{N}-50^{\circ} \mathrm{N}\right.$ and $\left.125^{\circ} \mathrm{W}-90^{\circ} \mathrm{W}\right)$. Figure 10 displays a systematic relationship between North American hydroclimate variability and EEP SST. In particular we note that on decadal time scales, the PDSI time series follows the Niño3.4 fluctuation. However, Fig. 10 also indicates that the American West is subjected to more severe droughts when the TNA is warmer than normal, compared to when it is colder than normal. In particular, the Dust Bowl, the 1950s drought, and the recent, turn of the century drought (Seager et al. 2007) occurred during cold equatorial Pacific events and an extended interval of warm TNA SSTs. In contrast, cold events in the Pacific did not affect the American West that severely when the TNA was in a cold state (e.g., around 1910 or in the mid-1970s).

- Figure 10 about here -

In the short interval corresponding to the era of satellite observations, the Atlantic related precipitation variability in North America is associated with dynamically consistent features surrounding North America over the Atlantic and Pacific Ocean Basins. Positive TNA SST anomalies in both halves of the hydrological year are associated with increased precipitation above and with a weakening of the Atlantic subtropical anticyclone (Fig. 2). A comparison with the output 
of the SST forced AGCMs (Fig. 3) indicates that these features are robust and that the change in subtropical Atlantic precipitation can be attributed to the change in SST. In the cold half of the hydrological year, a consistent string of changes over the Pacific, in both observations and model simulations, are found in connection with TNA SST variability. The tropical rainfall field displays a negative anomaly in the central equatorial Pacific, which is straddled by positive SLP anomalies in the extratropics of both hemispheres (Figs. 2 and 3).

Based on the similarity between model simulations and observations we argue that warmer than normal SST anomalies in the tropical Atlantic during the warm season, lead to increased convection there and that this forces a "Gill type" response that weakens the subtropical North Atlantic anticyclone. The resulting influence over North America is an anomalous southward flow and cold advection in the low troposphere, which leads to anomalous subsidence, via the heat and vorticity balances, over the American West as well as reduced moisture flux convergence, hence a suppression of rainfall anomalies. This hypothesis is confirmed with a linear AGCM forced with the tropical heating field associated with TNA SST anomalies in the full AGCM. The linear model results show that only the TNA portion of the tropical heating field can explain the Atlantic circulation response in both seasons.

In the cold season TNA heating anomalies alone cannot explain complex circulation features, which include an upstream impact on the North Pacific. Here we argue that increased convection in the TNA region, related to warm SSTs, lead to the suppression of convection over the central tropical Pacific. This is due to subsidence and to increased tropical static stability due to the spreading along the equator of the convective warming of the upper troposphere initiated in the Atlantic. The suppression of normal convection activity in the tropical Pacific forces a positive North Pacific pressure anomaly (a weakening of the seasonal Aleutian low), and atmospheric response which exacerbates the suppression of precipitation over the American West due to the 
Atlantic effect alone. This again is confirmed by the linear model experiments. It is worth noting that the influence of a TNA SST warming during the cold season on the North Pacific atmospheric circulation and American West precipitation yields a similar pattern to that of a typical La Niña event, though it is much weaker in magnitude. This is why a combination of a cold tropical Pacific (La Niña) and a warm tropical North Atlantic (c.f., the negative phase of the AMO), cause the most severe dry conditions over the western North America.

- Figure 11 about here -

It is interesting to compare the results of our study to those obtained in a more idealized set of experiments taken up by the U.S. CLIVAR “Drought Working Group.” In this organized activity (see http://www.usclivar.org/Organization/drought-wg.html) five different AGCMs were forced with fixed SST anomalies: one associated with the recent global SST trend, another with typical ENSO variations, and the third with AMO variability (Schubert et al. 2009). The CCM3 model used in the analysis presented here was included in the five sets of experiments. The models were run for 50 years, with these idealized anomalies added to and subtracted from the climatology. The "consensus" AGCM geopotential height response to a typical AMO SST change, shown in Fig. 11, is entirely consistent with the findings in this study (compare to Fig. 3, panels c and d), confirming the unexpected, indirect influence of Atlantic SST variability on the Pacific climate and the American West during the cold season as well as the more direct response in the warm season.

Acknowledgements: The authors acknowledge the support from NOAA awards NA03OAR4320179, NA08OAR4320754, and NA06OAR4310143. 


\section{References}

Acuna-Soto, R., D. W. Stahle, M. D. Therrell, S. G. Chavez, and M. K. Cleaveland, 2005: Drought, epidemic disease, and the fall of classic period cultures in Mesoamerica (AD 750-950): Hemorrhagic fevers as a cause of massive population loss. Med. Hypoth., 65, 405-409.

Basnett, T. and D. E. Parker, 1997. Development of the Global Mean Sea Level Pressure Data Set GMSLP2. Climate Research Technical Note 79, Hadley Centre, Met Office, Exeter, UK.

Biasutti, M., A. H. Sobel, and Y. Kushnir, 2006: AGCM precipitation biases in the tropical Atlantic. J. Climate, 19, 935-958.

Cassou, C., L. Terray, and A. S. Phillips, 2005: Tropical Atlantic influence on European heat waves. J. Climate, 18, 2805-2811.

Chen, M. Y., P. P. Xie, J. E. Janowiak, and P. A. Arkin, 2002: Global land precipitation: A 50-yr monthly analysis based on gauge observations. J. Hydrometeorol., 3, 249-266.

Cook, E. R., C. A. Woodhouse, C. M. Eakin, D. M. Meko, and D. W. Stahle, 2004: Long-term aridity changes in the western United States. Science, 306, 1015-1018.

Cook, B. I., R. L. Miller, and R. Seager, 2008: Dust and sea surface temperature forcing of the 1930's 'Dust Bowl' drought. Geophys. Res. Lett., Submitted.

Enfield, D. B., A. M. Mestas-Nunez, and P. J. Trimble, 2001: The Atlantic multidecadal oscillation and its relation to rainfall and river flows in the continental U.S. Geophys. Res. Lett., 28, 2077-2080.

Gill, A. E., 1980: Some Simple Solutions for Heat-Induced Tropical Circulation. Quart. J. Roy. Meteor. 
Soc., 106, 447-462.

Herweijer, C., R. Seager, and E. R. Cook, 2006: North American droughts of the mid to late nineteenth century: a history, simulation and implication for Mediaeval drought. Holocene, 16, 159-171.

Horel, J. D., and J. M. Wallace, 1981: Planetary-Scale Atmospheric Phenomena Associated with the Southern Oscillation. Mon. Wea. Rev., 109, 813-829.

Huang, H. P., R. Seager, and Y. Kushnir, 2005: The 1976/77 transition in precipitation over the Americas and the influence of tropical sea surface temperature. Clim. Dyn., 24, 721-740.

Huffman, G. J., R. F. Adler, P. A. Arkin, A. Chang, R. Ferraro, A. Gruber, J. E. Janowiak, A. McNab, B. Rudolf, and U. Schneider, 1997: The Global Precipitation Climatology Project (GPCP) combined precipitation data set. Bull. Amer. Meteorol. Soc., 78, 5-20.

Kalnay, E., M. Kanamitsu, R. Kistler, W. Collins, D. Deaven, L. Gandin, M. Iredell, S. Saha, G. White, J. Woollen, Y. Zhu, M. Chelliah, W. Ebisuzaki, W. Higgins, J. Janowiak, K. C. Mo, C. Ropelewski, J. Wang, A. Leetmaa, R. Reynolds, R. Jenne, and D. Joseph, 1996: The NCEP/ NCAR 40-Year Reanalysis Project. Bull. Amer. Meteorol. Soc., 77, 437-471.

Kaplan, A., M. A. Cane, Y. Kushnir, A. C. Clement, M. B. Blumenthal, and B. Rajagopalan, 1998: Analyses of global sea surface temperature 1856-1991. J. Geophys. Res.-Oceans, 103, 18567-18589.

Kiehl, J. T., J. J. Hack, G. B. Bonan, B. A. Bovile, D. L. Williamson, and P. J. Rasch, 1998: The National Center for Atmospheric Research Community Climate Model: CCM3. J. Climate, 11, 1131-1149.

Kistler, R., E. Kalnay, W. Collins, S. Saha, G. White, J. Woollen, M. Chelliah, W. Ebisuzaki, M. Kanamitsu, V. Kousky, H. van den Dool, R. Jenne, and M. Fiorino, 2001: The NCEP-NCAR 
50-year reanalysis: Monthly means CD-ROM and documentation. Bull. Amer. Meteorol. Soc., $82,247-267$.

Kushnir, Y., 1994: Interdecadal variations in North-Atlantic sea-surface temperature and associated atmospheric conditions. J. Climate, 7, 141-157.

McCabe, G. J., M. A. Palecki, and J. L. Betancourt, 2004: Pacific and Atlantic Ocean influences on multidecadal drought frequency in the United States. Proc. Natl. Acad. Sci., 101, 4136-4141.

Palmer, W.C., 1965. Meteorological drought. Research Paper, vol. 45. U.S. Weather Bureau.

Rayner, N. A., D. E. Parker, E. B. Horton, C. K. Folland, L. V. Alexander, D. P. Rowell, E. C. Kent, and A. Kaplan, 2003: Global analyses of sea surface temperature, sea ice, and night marine air temperature since the late nineteenth century. J. Geophys. Res.-Atmos., 108.

Schlesinger, M. E., and N. Ramankutty, 1994: An Oscillation in the Global Climate System of Period 65-70 Years. Nature, 367, 723-726.

Schubert, S. D., M. J. Suarez, P. J. Pegion, R. D. Koster, and J. T. Bacmeister, 2004a: Causes of longterm drought in the US Great Plains. J. Climate, 17, 485-503.

—, 2004b: On the cause of the 1930s Dust Bowl. Science, 303, 1855-1859.

Schubert, S. D. and co-authors, 2009: A USCLIVAR project to assess and compare the responses of Global Climate Models to drought-related SST forcing patterns: Overview and results. J. Climate, submitted.

Drought-Related SST Forcing Patterns: Overview and Results

Seager, R., 2007: The turn of the century North American drought: Global context, dynamics, and past analogs. J. Climate, 20, 5527-5552.

Seager, R., Y. Kushnir, M. Visbeck, N. Naik, J. Miller, G. Krahmann, and H. Cullen, 2000: Causes of 
Atlantic Ocean climate variability between 1958 and 1998. J. Climate, 13, 2845-2862.

Seager, R., N. Harnik, Y. Kushnir, W. A. Robinson, and J. Velez, 2003: Mechanisms of hemispherically symmetric climate variability. J. Climate, 16, 2160-2978.

Seager, R., A. R. Karspeck, M. A. Cane, Y. Kushnir, A. Kaplan, B. Kerman, and J. Velez, 2004: Predicting pacific decadal variability. Earth's Climate: The Ocean-Atmosphere Interaction, C. Wang, S.-P. Xie, and J. A. Carton, Eds., American Geophysical Union, Geophysical Monograph 147, 105-120.

Seager, R., N. Harnik, W. A. Robinson, Y. Kushnir, M. Ting, H. P. Huang, and J. Velez, 2005a: Mechanisms of ENSO-forcing of hemispherically symmetric precipitation variability. Quart. J. Roy. Meteor. Soc., 131, 1501-1527.

Seager, R., Y. Kushnir, C. Herweijer, N. Naik, and J. Velez, 2005b: Modeling of tropical forcing of persistent droughts and pluvials over western North America: 1856-2000. J. Climate, 18, 4065-4088.

Seager, R., and Coauthors, 2007: Model projections of an imminent transition to a more arid climate in southwestern North America. Science, 316, 1181-1184.

Seager, R., M.F. Ting, M. Davis, M.A. Cane, N. Naik, J. Nakamura, C. Li, E. Cook and D.W. Stahle, 2009: Mexican drought: An observational, modeling and tree ring study of variability and climate change, Atmosfera, 22, 1-31.

Sutton, R. T., and D. L. R. Hodson, 2005: Atlantic Ocean forcing of North American and European summer climate. Science, 309, 115-118.

Sutton, R. T., and D. L. R. Hodson, 2007: Climate response to basin-scale warming and cooling of the North Atlantic Ocean. J. Climate, 20, 891-907. 
Ting, M., and L. Yu, 1998: Steady response to tropical heating in wavy linear and nonlinear baroclinic models. J. Atmos. Sci., 35, 3565-3582.

Trenberth, K. E., G. W. Branstator, D. Karoly, A. Kumar, N. C. Lau, and C. Ropelewski, 1998: Progress during TOGA in understanding and modeling global teleconnections associated with tropical sea surface temperatures. J. Geophys. Res.-Oceans, 103, 14291-14324.

Visbeck, M., E. P. Chassignet, R. G. Curry, T. L. Delworth, R. R. Dickson, and G. Krahmann, 2002: The ocean's response to North Atlantic Oscillation variability. The North Atlantic Oscillation: Climatic Significance and Environmental Impact, J. W. Hurrell, Y. Kushnir, G. Ottersen, and M. Visbeck, Eds., American Geophysical Union, Geophysical Monograph Series Volume 134, 113-145.

Waliser, D. E., and C. H. Gautier, 1993: A satellite-derived climatology of the ITCZ. J. Climate, 6, $2162-2174$.

Wallace, J. M., and D. S. Gutzler, 1981: Teleconnections in the Geopotential Height Field During the Northern Hemisphere Winter. Mon. Wea. Rev., 109, 784-812.

Wang, G. L., 2005: Agricultural drought in a future climate: results from 15 global climate models participating in the IPCC 4th assessment. Clim. Dyn., 25, 739-753.

Yulaeva, E., and J. M. Wallace, 1994: The signature of ENSO in global temperature and precipitation fields derived from the Microwave Sounding Unit. J. Climate, 7, 1719-1736.

Zhang, Y., J. M. Wallace, and D. S. Battisti, 1997: ENSO-like decade-to-century scale variability: 1900-93. J. Climate, 10, 1004-1020. 


\section{Figure Captions}

Figure 1: Seasonal precipitation anomaly as a percent of the climatological RMS value for that season, associated with concomitant variations of tropical Atlantic SST (panels a and b) and ENSO variability (panels $\mathrm{c}$ and $\mathrm{d}$ ). Calculated using a multiple regression on the NINO3.4 and TNA SST indices. Panels a and c are for the cold season (October-March) and panels b and d are for the warm season (April-September). Contours are drawn every 10\% with negative contours dashed. The zero contour is bold. Shading is added to emphasize the main features. Data are from NOAA/NCEP/ PREC-L analysis (Chen et al. 2002) for the years 1948 to 2007.

Figure 2: Patterns of sea level pressure (SLP, contours every $0.2 \mathrm{hPa}$ ) and precipitation (colors in $\mathrm{mm} \mathrm{day}^{-1}$ ) anomalies associated with tropical Atlantic SST variability between 1979 and 2007. The effect of tropical Pacific SST variability (El Niño) was removed using multiple regression analysis on standardized NINO3.4 and TNA SST indices. Panel a is for the cold season (October-March) and panel $b$ is for the warm season (April-September). SLP is from the NCEP-NCAR Reanalysis Project (Kalnay et al. 1996; Kistler et al. 2001) and precipitation from GPCP (Huffman et al. 1997). The results of the analysis were smoothed in space with two passes of a binomial (1-2-1) filter to remove small-scale features, which are most likely associated with noise.

Figure 3: Same as in Fig. 2 but for the GOGA (left) and TAGA (right) model ensemble means. Data were not smoothed in space as the ensemble averaging leads to substantial reduction in the "noise" level (i.e., variability between one-ensemble member and another). Also, TAGA results are derived by a simple linear regression.

Figure 4. As in Fig. 1 but for precipitation derived from the GOGA model ensemble mean. Only the regression on the TNA SST index is shown. (a) October-March, (b) April-September. 
Figure 5: The vertically structure of the TAGA tropical $\left(20^{\circ} \mathrm{S}-20^{\circ} \mathrm{N}\right)$ heating anomaly, as determined by linearly regressing the three dimensional diabatic heating field, by season, on the TNA SST index. Panel a is for October-March and panel b is for April-September. Contours are every $0.04 \mathrm{~K} \mathrm{day}^{-1}$. Negative contours are dashed and the heavy black line is the zero contour. Gray shades are added to emphasize the main features.

Figure 6: Left panels: The TAGA warm-season streamfunction regression on the TNA SST index at the sigma level of .866 (panel a) and 0.17 (panel b). Right panels: The linear model streamfunction response to tropical heating at the same model levels, top (c) and bottom (d), respectively. Units are $10^{5} \mathrm{~m}^{2} \mathrm{sec}^{-1}$. Contour interval is 2 in the top panels and 10 in the bottom panels. Negative contours are dashed and the and the heavy black line is the zero contour. Shading is added to emphasize the main features.

Figure 7: Cold season streamfunction response in mid-troposphere (sigma level of 0.46). (a) The regression of the TAGA streamfunction field on the TNA SST index. (b)-(d) Linear model response to: (b) full tropical heating, (c) Atlantic only heating, (d) Pacific only heating. Units are $10^{5} \mathrm{~m}^{2} \mathrm{sec}^{-1}$. Contour interval is 2 and negative contours are dashed and the heavy black line is the zero contour.

Figure 8: Vertical cross section of the linear model cold-season (October-March) response to tropical Atlantic heating derived from the TAGA ensemble regression on the TNA SST index. (a) Vertical cross section of the vertical motion, contours every $0.310^{3}$ day $^{-1}$. (b) Same as (a) but for temperature, contours every $0.05^{\circ} \mathrm{C}$. Both fields are averaged between $20^{\circ} \mathrm{S}$ and $20^{\circ} \mathrm{N}$ and are plotted as a function of longitude and sigma level. The negative contours are dashed and the heavy black line is the zero contour.

Figure 9: Tropical region $\left(20^{\circ} \mathrm{S}-20^{\circ} \mathrm{N}\right)$ vertical cross section of the TAGA ensemble-mean temperature regressed on the TNA SST index. (a) Cold season (October-march) and (b) warm 
season (April-September). Contours every $0.05^{\circ} \mathrm{C}$, negative contours are dashed and the heavy black line is the zero contour.

Figure 10: The multi-model averaged $850 \mathrm{hPa}$ response to a North Atlantic wide SST anomaly calculated using the AGCMs participating in the CLIVAR Drought Working Group. All models were integrated for several decades with an SST anomaly resembling the change associated with the Atlantic Multidecadal Oscillation added to and subtracted from the climatological state (for the SST pattern see Schubert et al. 2009). The figure displays the difference between integrations forced with the positive and the negative phases of the anomaly. Panel a is for the cold-season response and panel $\mathrm{b}$ is for the warm season. Contours every $10 \mathrm{~m}$ with negative contours dashed and a solid thick zero contour. 

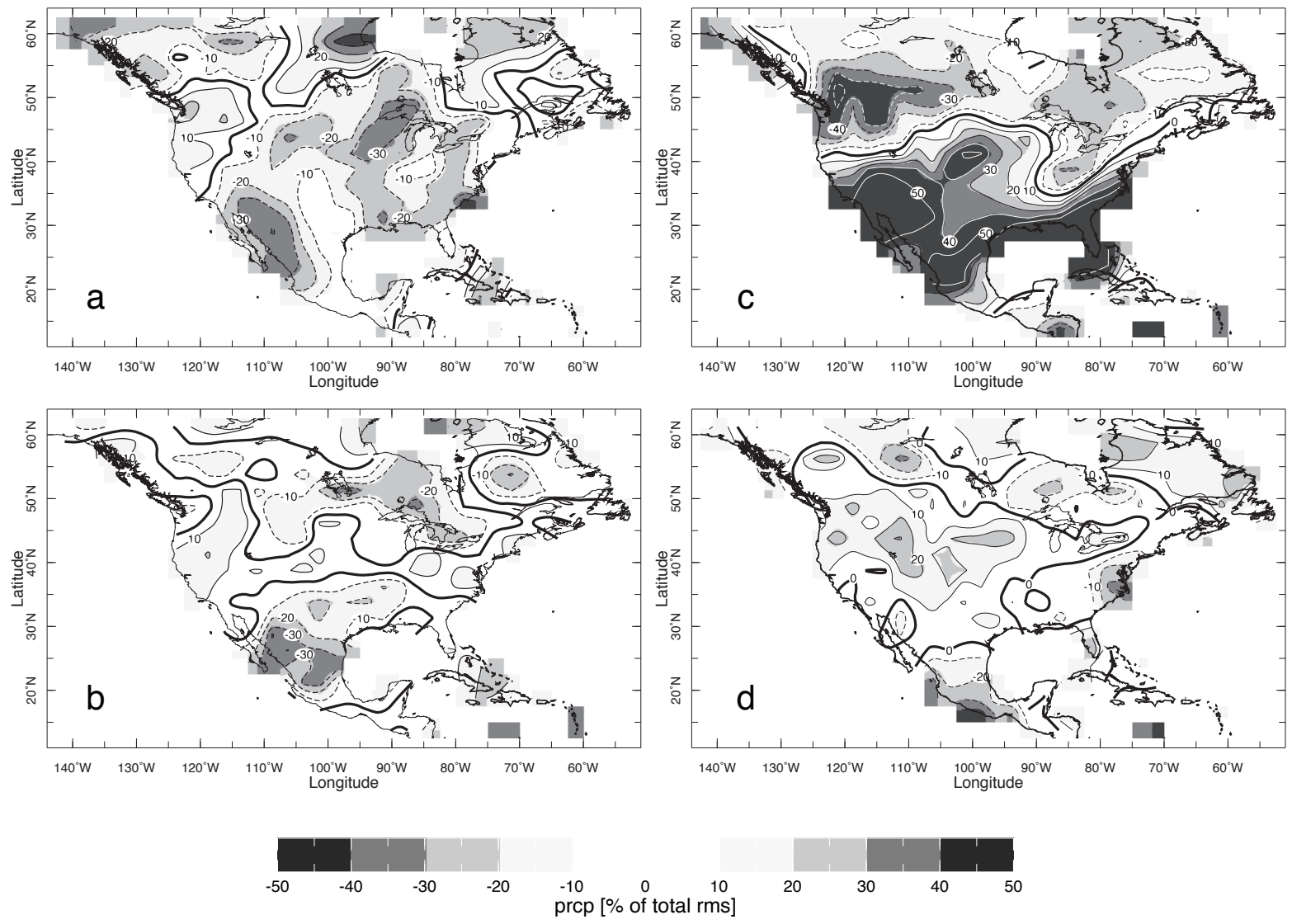

Figure 1: Seasonal precipitation anomaly as a percent of the climatological rms value for that season, associated with concomitant variations of tropical Atlantic SST (panels a and b) and ENSO variability (panels c and d). Calculated using a multiple regression on the NINO3.4 and TNA SST indices. Panels a and c are for the cold season (October-March) and panels b and d are for the warm season (April-September). Contours are drawn every 10\% with negative contours dashed. The zero contour is bold. Shading is added to emphasize the main features. Data are from NOAA/NCEP/ PREC-L analysis (Chen et al. 2002) for the years 1948 to 2007. 

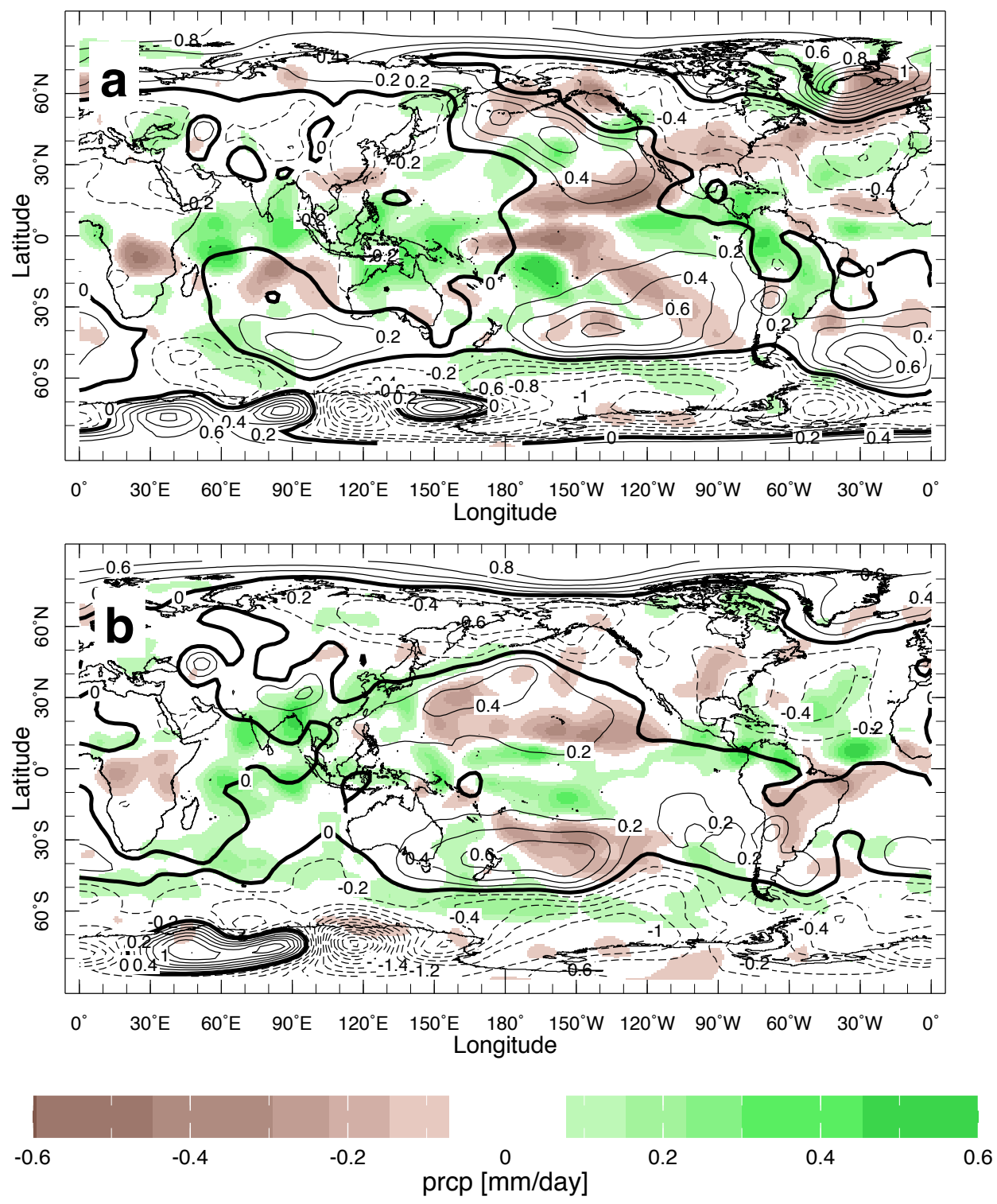

Figure 2: Patterns of sea level pressure (SLP, contours every $0.2 \mathrm{hPa}$ ) and precipitation (colors in $\mathrm{mm} \mathrm{day}^{-1}$ ) anomalies associated with tropical Atlantic SST variability between 1979 and 2007. The effect of tropical Pacific SST variability (El Niño) was removed using multiple regression analysis on standardized NINO3.4 and TNA SST indices. Panel $\mathrm{a}$ is for the cold season (October-March) and panel $b$ is for the warm season (April-September). SLP is from the NCEP-NCAR Reanalysis Project (Kalnay et al. 1996; Kistler et al. 2001) and precipitation from GPCP (Huffman et al. 1997). The results of the analysis were smoothed in space with two passes of a binomial (1-2-1) filter to remove small-scale features, which are most likely associated with noise. 
GOGA
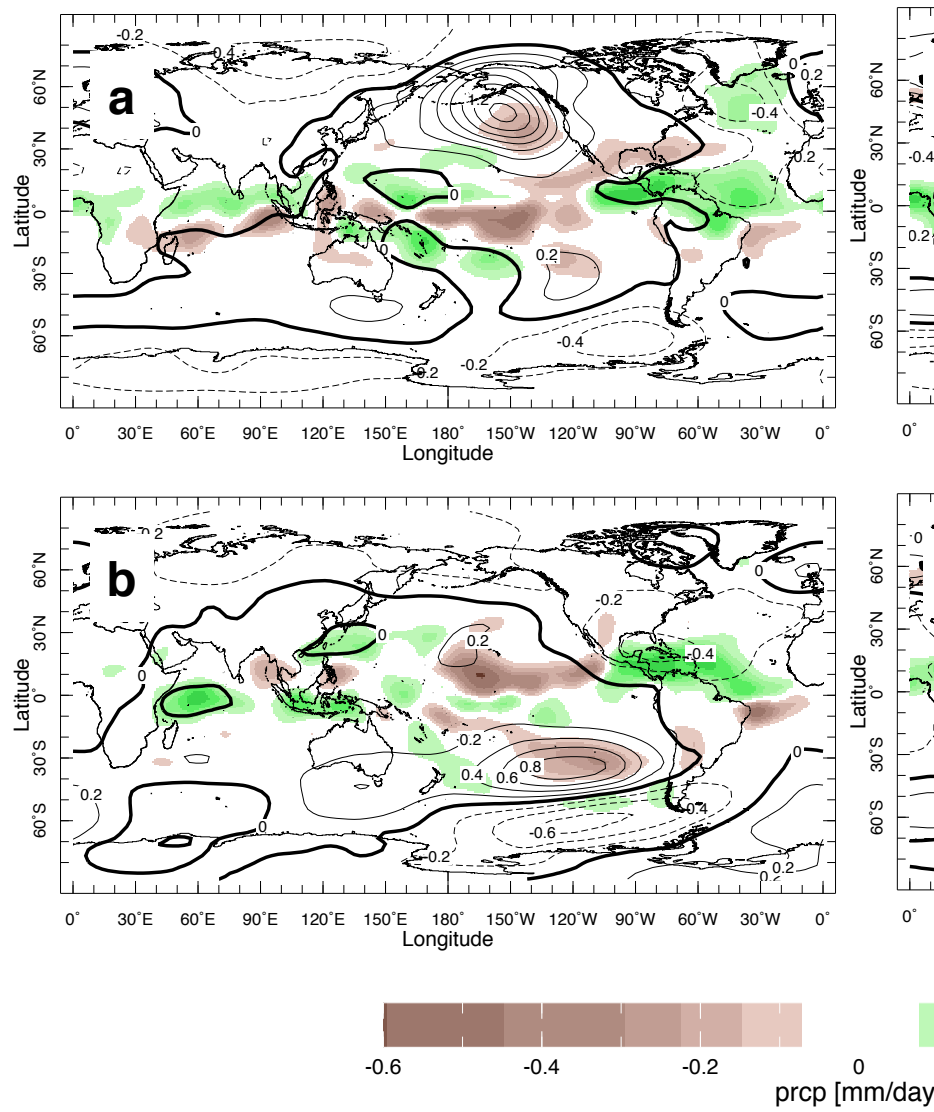

TAGA
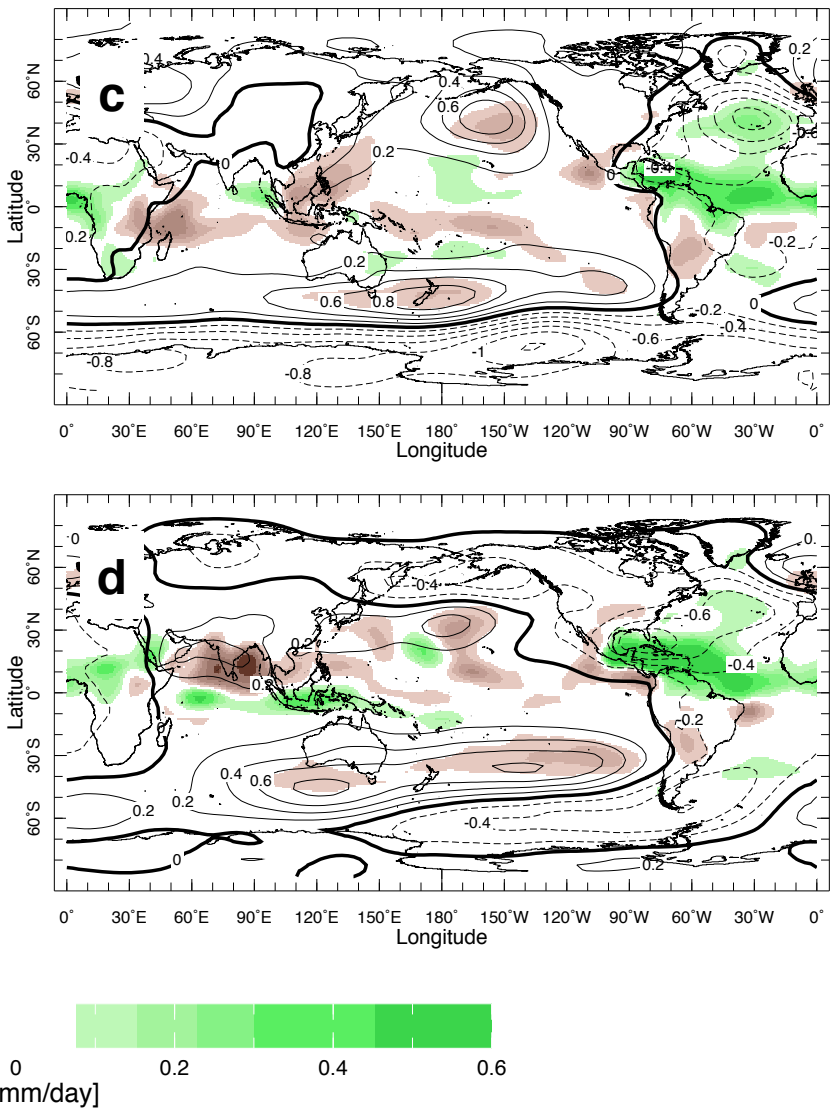

Figure 3: Same as in Fig. 2 but for the GOGA (left) and TAGA (right) model ensemble means. Data were not smoothed in space as the ensemble averaging leads to substantial reduction in the "noise" level (i.e., variability between one-ensemble member and another). Also, TAGA results are derived by a simple linear regression. 

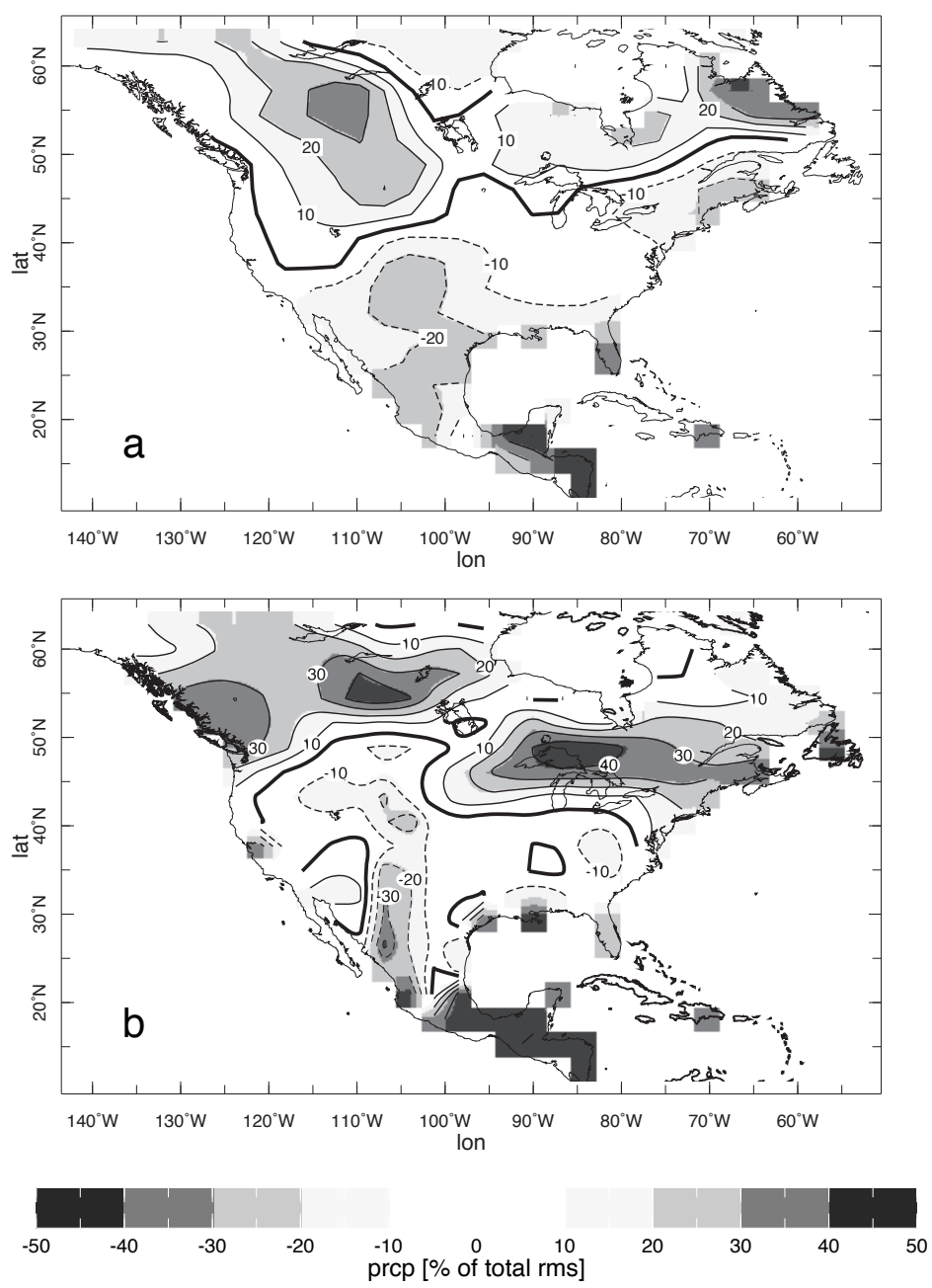

Figure 4. As in Fig. 1 but for precipitation derived from the GOGA ensemble mean. Only the regression on the TNA SST index is shown. (a) October-March, (b) April-September. 

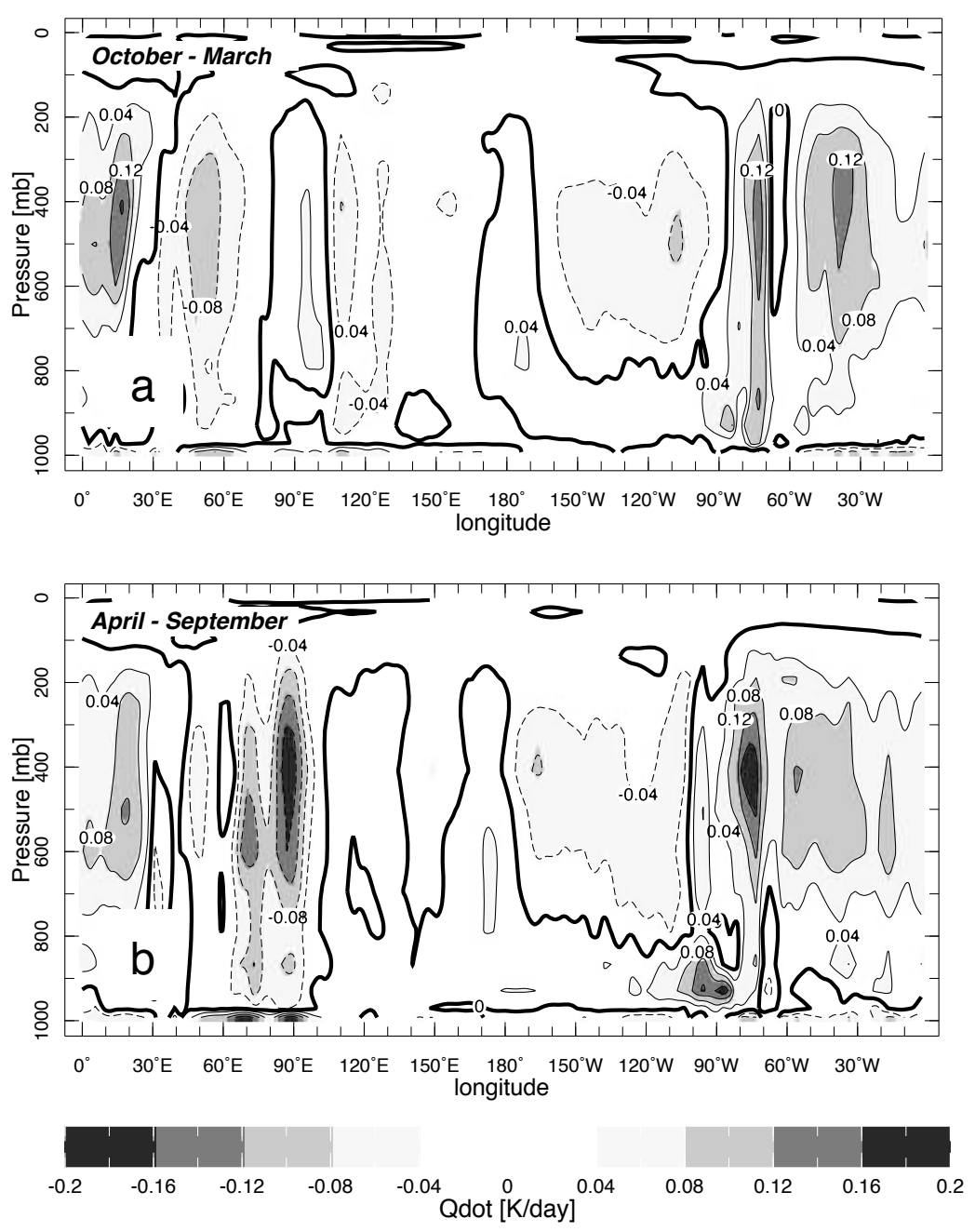

Figure 5: The vertically structure of the TAGA tropical $\left(20^{\circ} \mathrm{S}-20^{\circ} \mathrm{N}\right)$ heating anomaly, as determined by linearly regressing the three dimensional diabatic heating field, by season, on the TNA SST index. Panel a is for October-March and panel b is for April-September. Contours are every $0.04 \mathrm{~K} \mathrm{day}^{-1}$. Negative contours are dashed and the heavy black line is the zero contour. Gray shades are added to emphasize the main features. 

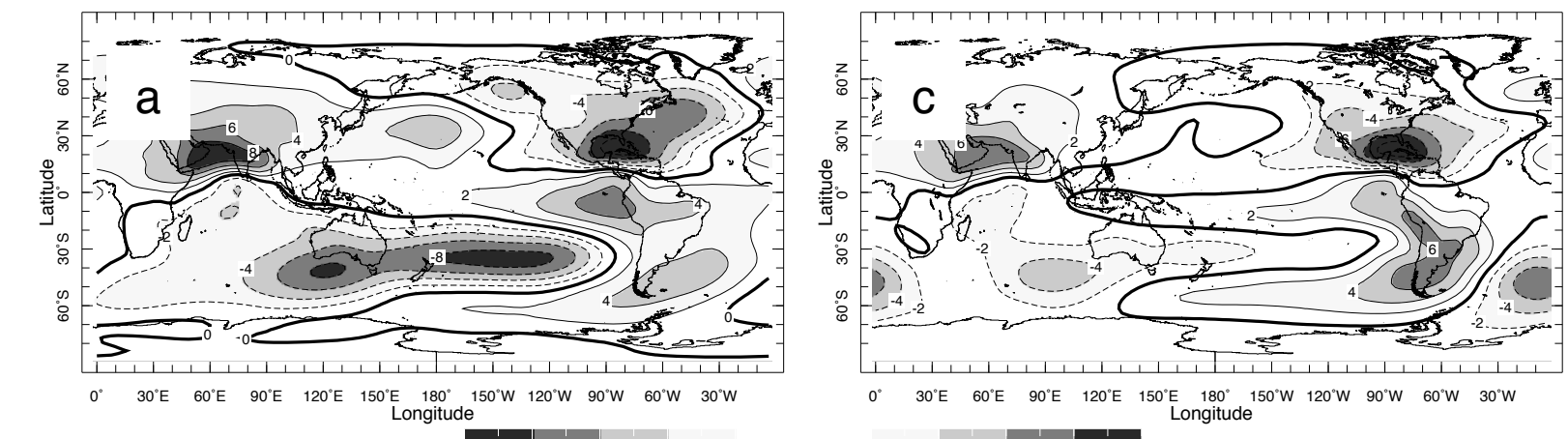

0.866
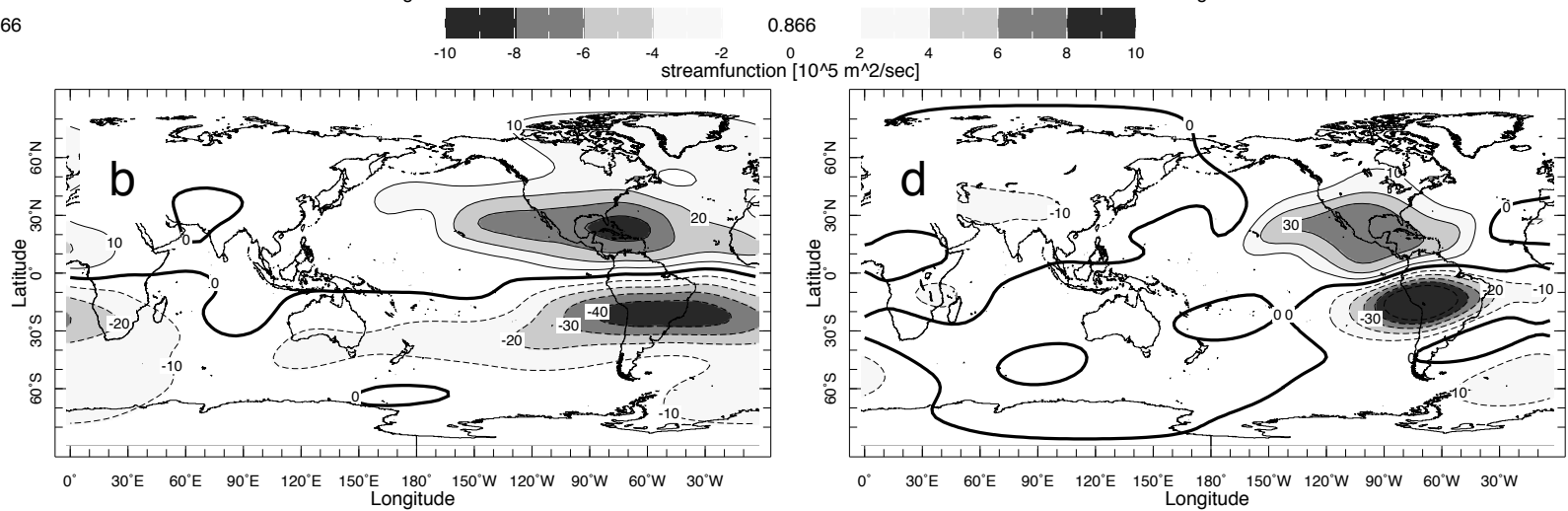

0.17

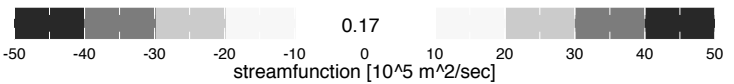

Figure 6: Left panels: The TAGA warm-season streamfunction regression on the TNA SST index at the sigma level of .866 (panel a) and 0.17 (panel b). Right panels: The linear model streamfunction response to tropical heating at the same model levels, top (c) and bottom (d), respectively. Units are $10^{5} \mathrm{~m}^{2} \mathrm{sec}^{-1}$. Contour interval is 2 in the top panels and 10 in the bottom panels. Negative contours are dashed and the and the heavy black line is the zero contour. Shading is added to emphasize the main features. 

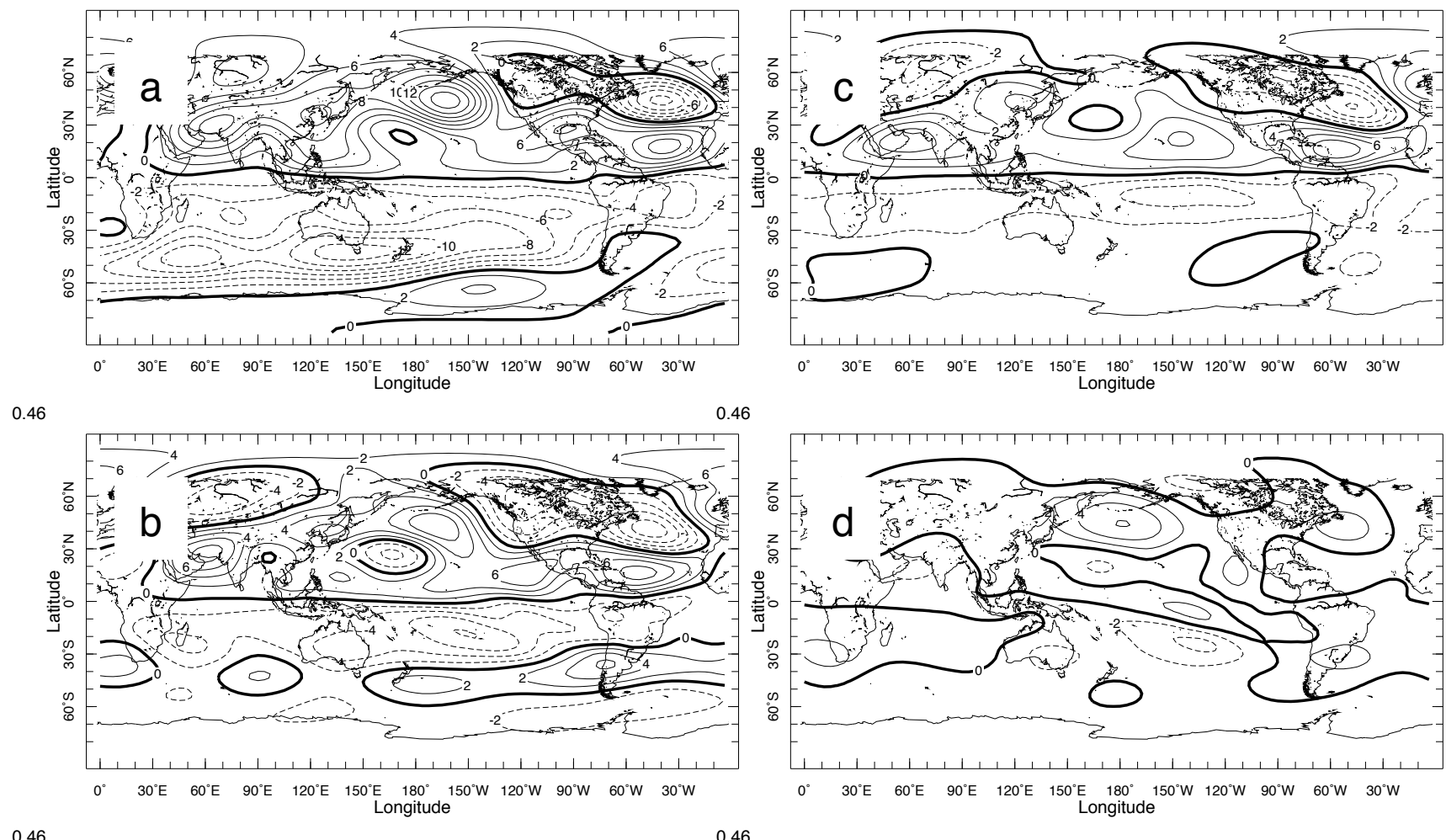

Figure 7: Cold season streamfunction response in mid-troposphere (sigma level of 0.46). (a) The regression of the TAGA streamfunction field on the TNA SST index. (b)-(d) Linear model response to: (b) full tropical heating, (c) Atlantic only heating, (d) Pacific only heating. Units are $10^{5} \mathrm{~m}^{2} \mathrm{sec}^{-1}$. Contour interval is 2 and negative contours are dashed and the heavy black line is the zero contour. 

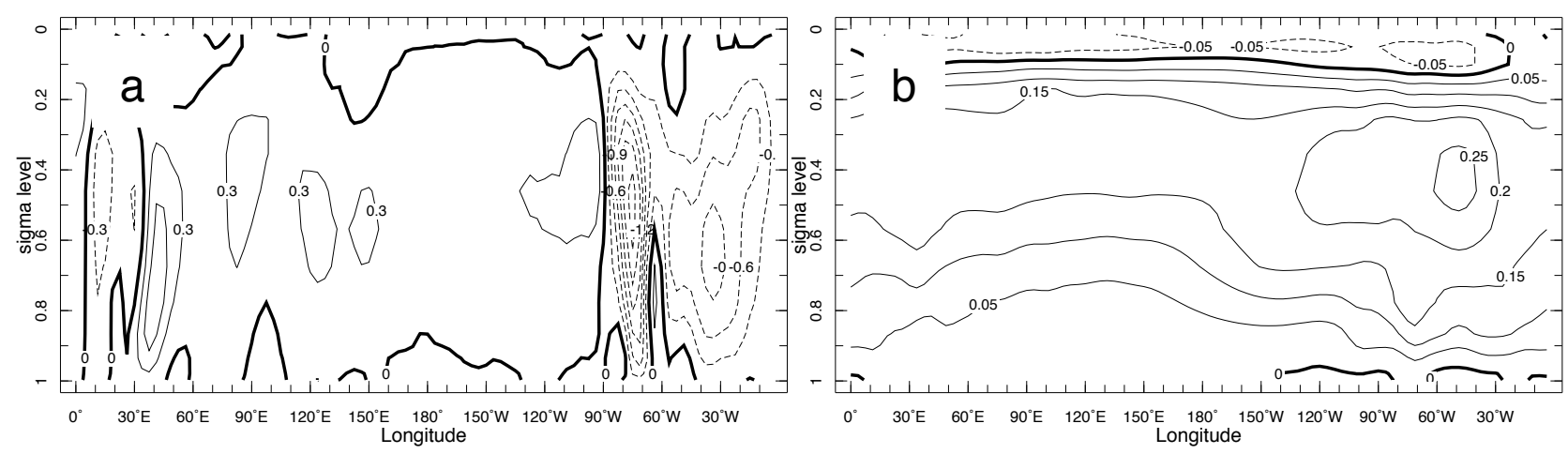

Figure 8: Vertical cross section of the linear model cold-season (October-March) response to tropical Atlantic heating derived from the TAGA ensemble regression on the TNA SST index. (a) Vertical cross section of the vertical motion, contours every $0.310^{3}$ day $^{-1}$. (b) Same as (a) but for temperature, contours every $0.05^{\circ} \mathrm{C}$. Both fields are averaged between $20^{\circ} \mathrm{S}$ and $20^{\circ} \mathrm{N}$ and are plotted as a function of longitude and sigma level. The negative contours are dashed and the heavy black line is the zero contour
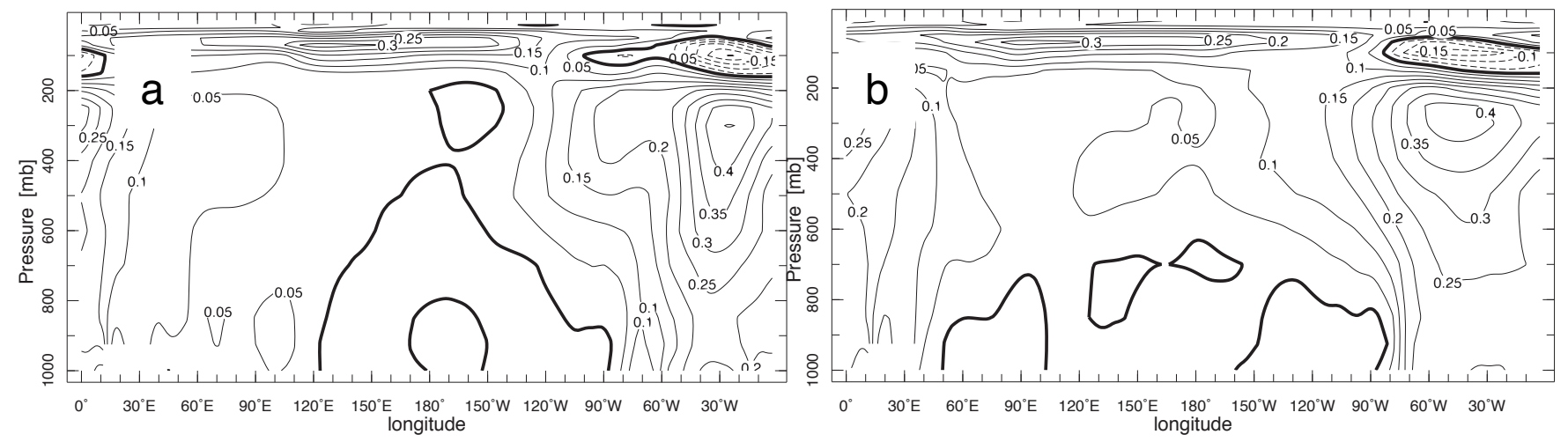

Figure 9: Tropical region $\left(20^{\circ} \mathrm{S}-20^{\circ} \mathrm{N}\right)$ vertical cross section of the TAGA ensemble-mean temperature regressed on the TNA SST index. (a) Cold season (October-march) and (b) warm season (April-September). Contours every $0.05^{\circ} \mathrm{C}$, negative contours are dashed and the heavy black line is the zero contour. 


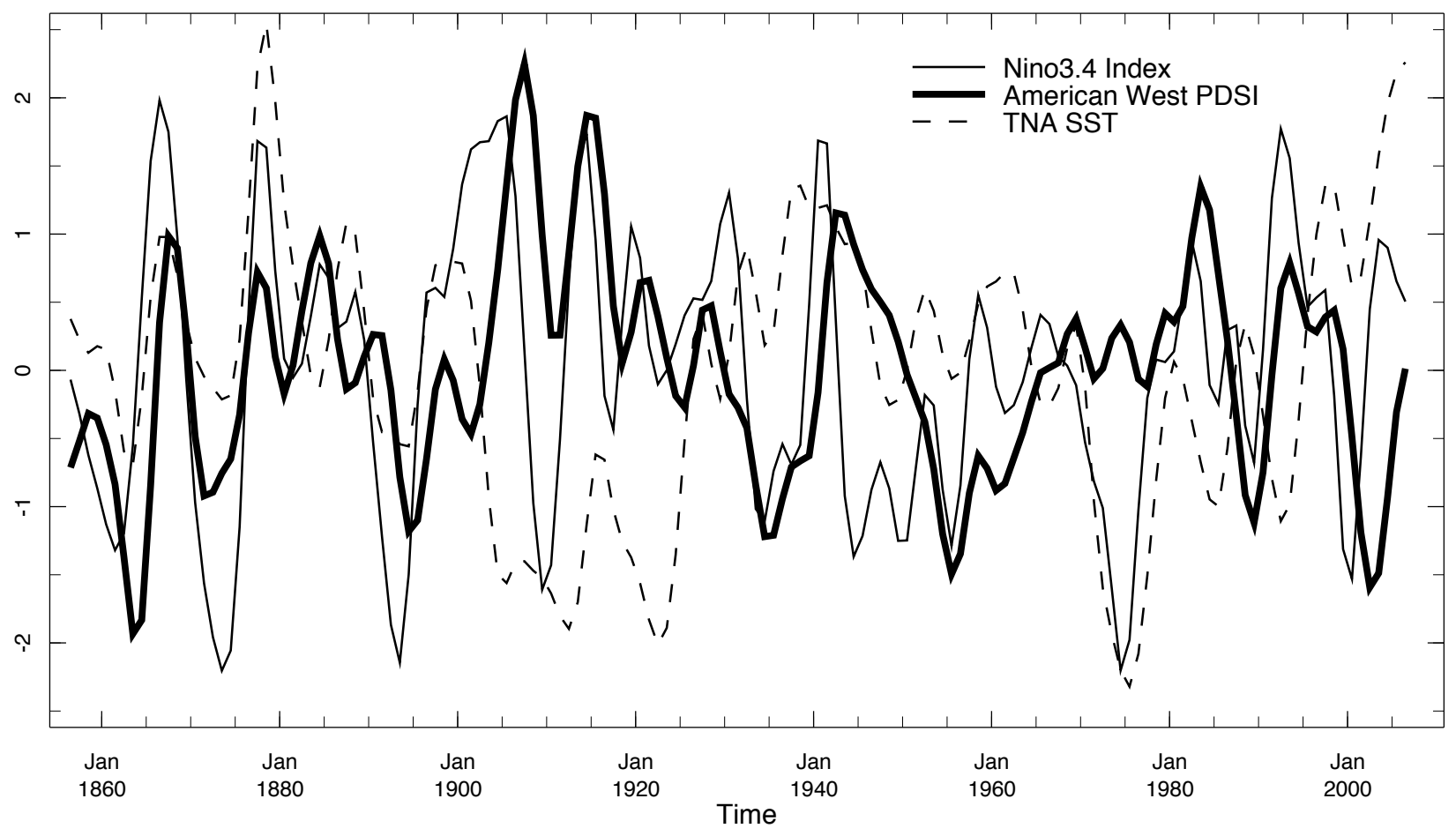

Figure 10: Annual Palmer Drought Severity Index (PDSI, from NADA, Cook et al. 2004) for the American West $\left(\left(25^{\circ} \mathrm{N}-50^{\circ} \mathrm{N}\right.\right.$ and $125^{\circ} \mathrm{W}-90^{\circ} \mathrm{W}$, thick black solid line $)$, the index of tropical North Atlantic SST (thin dashed line), and the Nino3.4 index (thin solid line). All time series are based on annual mean data low-pass filtered to emphasize fluctuations with periods of a decade and longer. All time series were linearly detrended in time to crudely remove the effect of global warming. The ordinate is in standardized values for Nino3.4 and the TNA index and in PDSI units for PDSI. 

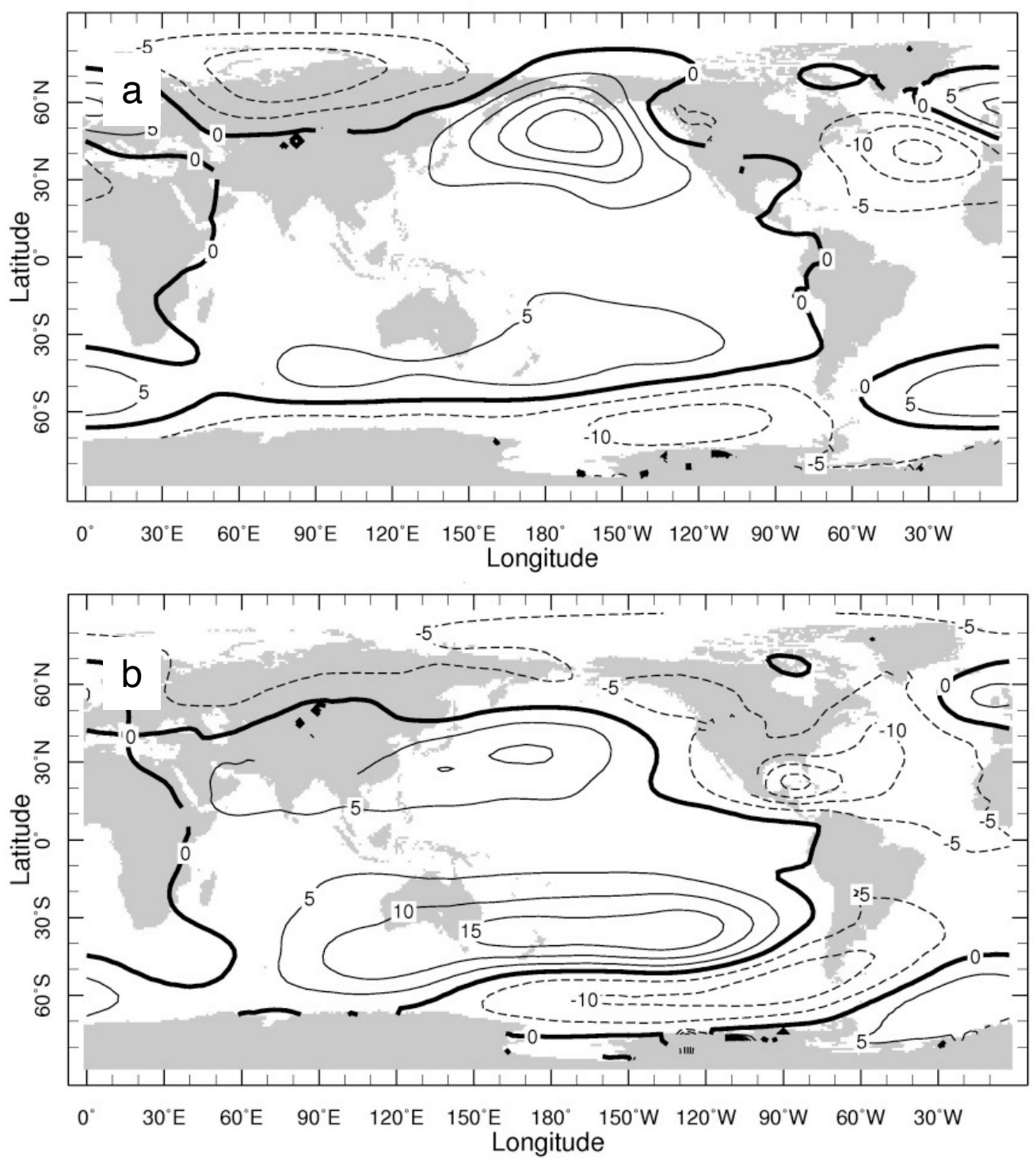

Figure 10: The multi-model averaged $850 \mathrm{hPa}$ response to a North Atlantic wide SST anomaly calculated using the AGCMs participating in the CLIVAR Drought Working Group. All models were integrated for several decades with an SST anomaly resembling the change associated with the Atlantic Multidecadal Oscillation added to and subtracted from the climatological state (for the SST pattern see Schubert et al. 2009). The figure displays the difference between integrations forced with the positive and the negative phases of the anomaly. Panel $\mathrm{a}$ is for the cold-season response and panel $\mathrm{b}$ is for the warm season. Contours every $10 \mathrm{~m}$ with negative contours dashed and a solid thick zero contour. 